$$
\text { JAPS J }
$$

DOI: https://doi.org/10.46730/japs.v1i1.2

\title{
Analisa Peran Tenaga Honorer Terhadap Efektivitas Tugas Aparatur Sipil Negara
}

\section{Rezkia Reisa Dora}

Kata kunci
Peran, Tenaga
Honorer, Efektivitas

Keywords

role, honorary

personnel,

effectiveness

\begin{abstract}
Abstrak
Salah satu faktor terlaksananya tugas Aparatur Sipil Negara adalah adanya peran tenaga honorer di setiap intansi Pemerintahan. Di Kantor Kecamatan Rangsang Barat sebagian tugas Aparatur Sipil Negara diserahkan kepada tenaga honorer. Namun, adanya ketidakjelasan tugas pada setiap tenaga honorer menyebabkan peran tenaga honorer ini tidak efektif. Permasalahan peran tenaga honorer ini telah penulis angkat ke dalam penelitian. Tujuan dari penelitian ini adalah untuk menganalisa faktor - faktor lain yang menyebabkan tidak efektifnya peran tenaga honorer serta memberikan solusi dari permasalahan. Penelitian ini menggunakan metode deskriptif kualitatif. Dalam menganalisis peran tenaga honorer di Kantor Kecamatan Rangsang Barat, peneliti melihat dari tiga faktor, yaitu tugas pokok Aparatur Sipil Negara, kriteria dan prosedur pengangkatan tenaga honorer, dan pelaksanaan tugas tenaga honorer di Kantor Kecamatan Rangsang Barat. Berdasarkan ketiga faktor tersebut dapat disimpulkan bahwa peran tenaga honorer di Kantor Kecamatan Rangsang Barat kurang efektif.
\end{abstract}

\begin{abstract}
One of the factors of the implementation of the task of the State Civil Apparatus is the role of honorary personnel in each Government agency. In the Rangsang Barat District Office, part of the State Civil Apparatus task was handed over to honorary personnel. However, there is a lack of clarity in the assignment of each honorary staff, causing the role of honorary personnel to be ineffective. The issue of the role of honorary workers has been raised by the authors in the research. The purpose of this research is to analyze other factors that cause ineffectiveness of the role of honorary personnel and provide solutions to problems. This study used descriptive qualitative method. In analyzing the role of honorary personnel in the Rangsang Barat District Office, researchers looked at three factors, namely the main tasks of the State Civil Apparatus, the criteria and procedures for the appointment of honorary personnel, and the implementation of the duties of honorary personnel at the Rangsang Barat District Office. Based on these three factors it can be concluded that the role of honorary workers in the Rangsang Barat District Office is less effective.
\end{abstract}




\section{Pendahuluan}

Berdasarkan Undang- Undang Nomor 43 tahun 1999 tentang Perubahan Atas Undang-Undang Nomor 8 tahun 1974 tentang Pokok - Pokok Kepegawaian Pasal 2 ayat (3) diakui tentang peran tenaga honorer yang diimplementasikan dalam struktur sumber daya aparatur Indonesia, yang berfungsi membantu pelaksanaan tugas - tugas pemerintahan dan pelayanan pada masyarakat khususnya di daerah. Tenaga honorer dibutuhkan di setiap instansi Pemerintahan atau Pemerintah Daerah untuk membantu tugas - tugas Aparatur Sipil Negara yaitu memberikan pelayanan kepada masyarakat secara profesional, jujur, adil dan merata dalam penyelenggaraan tugas negara, pemerintahan dan pembangunan.

Tenaga honorer dalam pengertiannya banyak yang menafsirkan lain tanpa mengarah kepada dasar hukum yang ada saat ini, seperti halnya yang terjadi dalam paradigma sekarang tenaga honorer ada yang mengartikan sebagai Tenaga Honorer APBD/APBN dan Tenaga Honorer Non-APBD/APBN serta Pegawai Tidak Tetap (PTT) itu sendiri. Apalagi setelah munculnya Peraturan Pemerintah Nomor 48 Tahun 2005 tentang Pengangkatan Tenaga Honorer Menjadi Pegawai Negeri Sipil dan Peraturan Pemerintah Nomor 43 Tahun 2007 tentang Perubahan Atas Peraturan Pemerintah Nomor 48 Tahun 2005 tentang Pengangkatan Tenaga Honorer Menjadi Calon Pegawai Negeri Sipil dan diubah untuk kedua kalinya dengan Peraturan Pemerintah Nomor 56 Tahun 2012 tentang Perubahan Kedua Peraturan Pemerintah Nomor 48 Tahun 2005 tentang Pengangkatan CPNS dari Tenaga Honorer. Adapun berdasarkan Pasal 1 ayat (1) Peraturan Pemerintah Nomor 48 Tahun 2005 tentang Pengangkatan CPNS dari Tenaga Honorer yang dimaksud dengan tenaga honorer adalah: Sampai saat ini masyarakat masih tergiur dengan pekerjaan sebagai tenaga honorer di kantor- kantor Pemerintahan. Masyarakat masih berpikir dengan menjadi tenaga honorer maka kesempatan untuk diangkat menjadi CPNS akan lebih besar. Kebijakan penerimaan tenaga honorer di setiap daerah berbeda - beda, sesuai dengan kebutuhan. Sejalan dengan tugas Aparatur Sipil Negara dalam pelayanan publik, maka peran tenaga honorer yang memiliki pendidikan tinggi dan kemampuan dalam menyelesaikan segala pekerjaan juga sangat tinggi.

"Seseorang yang diangkat oleh Pejabat Pembina Kepegawaian atau pejabat lain dalam pemerintahan untuk melaksanakan tugas tertentu pada instansi pemerintah atau yang penghasilannya menjadi beban Anggaran Pendapatan dan Belanja Negara atau Anggaran Pendapatan dan Belanja Daerah.",

Tenaga honorer dalam perkembangannya bertujuan untuk membantu kinerja PNS yang mana PNS tersebut sudah kewalahan dalam menjalankan fungsi dari pemerintah daerah yaitu salah satunya dalam hal pelayanan publik yang merupakan fungsi dari Pemerintah Daerah itu sendiri. ${ }^{2}$ Dari hasil pengamatan peneliti sejauh ini, seringkali dijumpai penerimaan tenaga honorer khususnya di daerah tidak melalui prosedur yang jelas. Istilah "orang dalam" sangat melekat jika dihubungkan dengan pengangkatan tenaga honorer. Tidak adanya syarat-syarat khusus seperti jenjang 
pendidikan minimal yang harus dimiliki calon tenaga honorer menyebabkan banyakanya tenaga honorer yang hanya memiliki jenjang pendidikan SMA atau setara.

Padahal jika dihubungkan dengan tugas pokok Aparatur Sipil Negara, tenaga honorer juga harus memiliki jenjang pendidikan yang memadai karena peran tenaga honorer dalam membantu tugas Aparatur Sipil Negara baik di kantor atau di lapangan setidaknya tenaga honorer harus memiliki pemahaman tentang manajemen, IT, sistem pelayanan publik dan sebagainya. Namun perlu ditegaskan disini bahwa tenaga honorer hanya membantu tugas Aparatur Sipil Negara bukan menggantikan peran ataupun tugas pokok Aparatur Sipil Negara.

Di Kabupaten Kepulauan Meranti, berdasarkan hasil pengamatan peneliti, sampai tahun 2019 masih ditemukan penerimaan tenaga honorer yang diangkat oleh masing - masing kantor atau satuan kerja tanpa melalui prosedur yang jelas dan syarat syarat yang ditetapkan. Padahal peraturan dari Pemerintah Daerah, sejak tahun 2015 ditegaskan tidak ada penerimaan bagi pegawai honorer lagi. Jumlah tenaga honorer yang terlalu banyak disetiap kantor atau satuan kerja menyebabkan peran tenaga honorer sudah tidak efektif lagi. Seringkali tenaga honorer hanya datang saja tanpa mengerjakan apapun. Salah satu kantor yang ada di Kabupaten Kepulauan Meranti yang menjadi objek penelitian peneliti adalah Kantor Kecamatan Rangsang Barat. Kantor kecamatan sesuai dengan Peraturan Menteri Dalam Negeri Nomor 4 Tahun 2010 tentang Pedoman Pelayanan Administrasi Terpadu Kecamatan merupakan salah satu pelaksana penyelenggara pelayanan publik di Kecamatan dari tahap permohonan sampai ke tahap terbitnya dokumen dalam satu tempat.

\section{Metode}

\section{Tipe Penelitian}

Penelitian ini menggunakan tipe deskriptif kualitatif yang dimaksudkan untuk memberi gambaran mengenai fenomena dan menganalisa peran, kendala, dan solusi untuk meningkatkan peran pegawai honorer terhadap efektivitas tugas Aparatur Sipil Negara.

\section{Lokasi Penelitian}

Penelitian ini dilakukan di Kantor Kecamatan Rangsang Barat Kabupaten Kepulauan Meranti. Lokasi penelitian ini dipilih karena didasarkan kondisi yang sesuai dengan tema penelitian.

\section{Teknik Pengumpulan Data}

Data yang dikumpulkan akan dijadikan sebagai bahan untuk analisis. Data yang diperlukan dalam penelitian ini adalah data primer dan sekunder. Data primer merupakan data yang diperoleh secara langsung dari lokasi penelitian melalui wawancara dengan informan yang berkaitan dengan masalah penelitian, dan juga melalui observasi atau pengamatan langsung terhadap objek penelitian.

Sedangkan data sekunder adalah data yang diperoleh dalam bentuk uraian. Dalam penelitian ini data - data sekunder yang diperlukan antara lain : literatur yang relevan dengan judul penelitian, misalnya materi atau dokumen - dokumen dari kantor 
Kecamatan Rangsang Barat serta buku - buku dan karya ilmiah yang relevan dengan penelitan. Dalam penelitian ini, teknik pengumpulan data yang digunakan oleh penulis dalam memperoleh data - data yang di butuhkan yaitu melalui beberapa teknik pengumpulan data sebagai berikut:

1. Pengamatan (observation)

Observasi yaitu melakukan pengamatan secara langsung ke objek penelitian untuk melihat dari dekat kegiatan yang dilakukan . Apabila objek penelitian bersifat perilaku dan tindakan manusia (kejadian - kejadian yang terjadi)

2. Wawancara

Wawancara adalah suatu cara pengumpulan data yang digunakan untuk memperoleh informasi langsung dari sumbernya. Pewawancara adalah pengumpul informasi yang diharapkan dapat meyampaikan pertanyaan dengan jelas dan kemudian menulis semua jawaban dari pemberi informasi (Informan)

3. Dokumentasi

Data ini dikumpulkan dengan melalui berbagai sumber data yang tertulis baik yang berhubungan dengan masalah kondisi objektif, juga silsilah dan pendukung data lainnya.

\section{Fokus Penelitian}

Fokus dalam penelitian ini adalah analisis peran Tenaga Honorer terhadap efektivitas tugas Aparatur Sipil Negara di Kantor Kecamatan Rangsang Barat

\section{Hasil dan Pembahasan}

Dalam melakukan analisis peran tenaga honorer di Kantor Kecamatan Rangsang Barat, penulis melihat dari beberapa faktor yang diuraikan sebagai berikut :

\section{Uraian Tugas Pegawai Negri Sipil di Kantor Kecamatan Rangsang Barat}

Salah satu tugas Pegawai Negeri Sipil di Kantor Camat tertuang dalam Peraturan Bupati Nomor 16 Tahun 2015 tentang uraian tugas pelaksana pelayanan administrasi terpadu Kecamatan di Kabupaten Kepulauan Meranti, diuraikan tentang pejabat penyelenggara PATEN (Pelayanaan Administrasi Terpadu Kecamatan). Dalam pasal 9 disebutkan bahwa pelaksana teknis PATEN meliputi :

a. Petugas Informasi

b. Petugas Loket/ Penerima Berkas

c. Petugas operator computer

d. Petugas pemegang kas

e. Petugas lain sesuai kebutuhan

Pelaksana teknis sebagaimana dimaksud adalah Pegawai Negeri Sipil di Kecamatan yang ditetapkan oleh Camat. Adapun personil pelaksana teknis sebagaimana dimaksud dalam Perbup Nomor 16 Tahun 2015 terdiri dari :

a. Petugas informasi, 2 (dua) orang atau disesuaikan dengan kebutuhan; 
b. Petugas loket/ penerima berkas, maksimal 8 (delapan)/ 8 (delapan) loket atau disesuaikan dengan kondisi daerah Kecamatan;

c. Petugas operator komputer, maksimal 2 (dua) orang, diperlukan cadangan bila ditunjuk berhalangan hadir;

d. Petugas pemegang kas, 1 (satu) orang

Dari hasil pengamatan dan wawancara dengan beberapa pegawai negeri sipil serta tenaga honorer, semua pelaksana PATEN dilakukan oleh tenaga honorer kecuali pemegang kas.

\section{Kriteria dan Prosedur Pengangkatan Tenaga Honorer di Kantor Camat Rangsang Barat}

Kriteria dalam pengangkatan pegawai/ karyawan sangat diperlukan dalam sebuah instansi baik Pemerintah maupun swasta. Hal ini akan berpengaruh kepada kinerja para pegawai/ karyawan dalam melaksanakan setiap pekerjan yang diemban. Kriteria meliputi tingkat pendidikan, umur, kecakapan, disiplin, kemampuan bekerja dalam tim, hasil tes baik secara lisan ataupun tulisan, dll. Dari hasil pengamatan dan wawancara dengan kepala bagian umum di Kantor Kecamatan Rangsang Barat, dalam melakukan perekrutan/ penerimaan tenaga honorer di Kantor Kecamatan Rangsang Barat tidak melalui prosedur ataupun dari kriteria - kriteria yang jelas dan ditetapkan. Semua tenaga honorer yang ada merupakan "titipan orang dalam".

Tabel 1. Tingkat Pendidikan Tenaga Honorer di Kantor Kecamatan Rangsang Barat

\begin{tabular}{lll}
\hline No & Pendidikan & Jumlah \\
\hline 1 & SLTP & 2 orang \\
2 & SLTA & 15 orang \\
3 & D3 & 3 orang \\
4 & S1 & - \\
Total & & $\mathbf{2 0 ~ 0 r a n g}$ \\
\hline
\end{tabular}

Berdasarkan Data yang didapat dari Kantor Camat Rangsang Barat di bawah ini di atas dapat dilihat bahwa hampir seluruhnya tenaga honorer hanya memiliki jenjang pendidikan SLTA. 3 (tiga) orang yang memiliki jenjang pendidikan Diploma 3 inipun ketika diangkat menjadi tenaga honorer hanya memiliki jenjang pendidikan SLTA. Pendidikan D3 diambil ketika para tenaga honorer sudah bekerja di Kantor tersebut. Rendahnya tingkat pendidikan tenaga honorer yang ada berpengaruh kepada proses pelaksanaan dan penyelesaian tugas. Tenaga honorer ini seringkali tidak mengerti dengan tugas yang diberikan. Akibatnya tenaga honorer hanya diberikan tugas menerima berkas, memfotocopy surat atau dokumen, atau hanya mengantar surat. 


\section{Pelaksanaan Tugas Tenaga Honorer Di Kantor Camat Rangsang Barat}

Berdasarkan informasi dan data yang diperoleh dari informan di Kantor Camat Rangsang Barat, berdasarkan Peraturan Bupati sejak tahun 2015 sudah tidak ada lagi penerimaan tenaga honorer. Namun pada kenyataannya, di Kantor Camat Rangsang Barat, pada tahun 2019 masih ada pengangkatan tenaga honorer. Tenaga honorer ini diangkat oleh kantor. Dalam melakukan perekrutan tenaga honorer tidak ada prosedur dan syarat - syarat yang ditetapkan. Hal ini menyebabkan kualitas calon tenaga honorer tidak dapat terukur pada saat penerimaan.

Tenaga honorer ini bekerja atas perintah dari Pegawai Negeri Sipil yang ada di Kantor Camat. Namun dalam pelaksanaan tugas dan tanggung jawab, tenaga honor seharusnya bekerja sesuai denga tupoksi dari SK yang telah ditetapkan oleh kantor yang dalam hal ini adalah Camat sebagai penanggung jawab. Kenyataan di lapangan, para tenaga honorer ini bekerja tidak sesuai dengan SK yang mereka diterima. Dapat dilihat dari data berikut :

Tabel 2. Jumlah Tenaga Honorer di Kantor Kecamatan Rangsang Barat

\begin{tabular}{lll}
\hline No & Bidang & Jumlah Tenaga Honorer \\
\hline 1 & Jasa Paten & 6 orang \\
2 & Jasa Kebersihan & 7 orang \\
3 & Jasa Keamanan & 7 orang \\
\hline
\end{tabular}

Sumber : Data Tenaga Honorer Kantor Camat Rangsang Barat 2019

Dari data di atas, diakui oleh Kepala Bagian Umum, tenaga hororer jasa paten yang sekarang disebut tenaga lepas harian berdasarkan SK berjumlah 6 orang yang membantu tugas pegawai negeri yang ada di Kantor Camat. Para tenaga honorer ini diperbantukan di bagian informasi, loket penerima berkas, dan operator komputer. Tenaga honorer di bidang kebersihan dan jasa keamanan masing - masing berjumlah 7 orang. Namun dalam kenyataan dalam pekerjaan, tenaga honorer ini bukan sebagai petugas kebersihan dan keamanan. Tenaga honorer ini bekerja sebagai tenaga jasa paten. Tenaga honorer di bagian jasa kebersihan dan jasa keamanan yang bekerja sesuai dengan tupoksi masing-masing hanya 2 orang.

Jika diteliti, jumlah tenaga honorer yang bertugas di bidang jasa paten terlalu banyak, mengingat Kantor Kecamatan Rangsang Barat bukan kantor besar. Kantor ini hanya memiliki 1 (satu) loket pelayanan penerima berkas. Jumlah komputer di kantor ini juga sangat sedikit, tidak semua ruangan memiliki komputer. Bahkan beberapa ruangan tidak memiliki komputer/ laptop. Dari pengamatan langsung yang dilakukan peneliti, tenaga honorer di kantor kecamatan Rangsang Barat ini sangat tidak efektif. Sebagian besar hanya datang dan duduk saja tanpa melakukan pekerjaan apapun. Para tenaga honorer ini hanya melakukan perintah ketika pegawai memberikan perintah tugas. 
Efektivitas peran tenaga honorer sangat terkait dengan kebijakan Camat atau kepala bagian umum yang bertanggung jawab terhadap kepegawaian dan pelaksanaan tupoksi tenaga honorer/ tenaga pembantu pelaksana PATEN. Seharusnya tenaga honorer yang ada diberikan tugas sesuai dengan SK yang diterbitkan. Selain itu, tenaga honorer sebaiknya dibagi di setiap bagian/ ruangan dan hanya melakukan tugas pada bagian/ ruangan yang telah ditatapkan. Selain yang dijelaskan di atas, di Kantor Camat juga terdapat beberapa bagian/ unit yaitu PMD, Kesosbud, Pemerintahan, Program dan Perencanaan, Keuangan, ketentraman \& Ketertiban. Dalam pelaksanaan tugas, dari hasil pengamatan yang dilakukan dan wawancara dengan para pegawai, sampai saat ini tidak ada peraturan ataupun kebijakan dari Camat tentang pembagian tugas kepada tenaga honorer. Tenaga honorer yang ada. Peran Pegawai Negeri Sipil/ ASN juga sangat penting. Mengingat para tenaga honorer ini bertugas membantu pekerjaan para PNS agar dapat selesai dengan baik dan tepat waktu. Para PNS sebaiknya mendampingi para tenaga honorer dalam melaksanakan tugas - tugas yang diberikan.

\section{Simpulan}

Dari hasil penelitian yang telah diuraikan, dapat disimpulkan beberapa temuan penting, yaitu :

1. Pelaksana PATEN di kantor Camat Rangsang Barat adalah tenaga honorer kecuali pemegang kas, seharusnya sesuai dengan Peraturan Bupati Nomor 16 tahun 2015, pelaksana PATEN haruslah pegawai negeri sipil/ ASN. Tenaga honorer hanyalah sebagai pembantu atau tenaga pendamping saja.

2. Perekrutan atau pengangkatan tenaga honorer tidak melalui prosedur yang jelas serta tidak ada kriteria - kriteria khusus yang ditetapkan. Rendahnya tingkat pendidikan tenaga honorer menyebabkan kurangnya kemampuan para tenaga honorer dalam memahamai dan melaksanakan tugas.

3. Jumlah tenaga honorer di bagian kebersihan dan keamanan yang terlalu banyak serta tidak ada pembagian tugas yang jelas menyebabkan peran tenaga honorer dalam membantu pegawai negeri di Kantor Camat kurang efektif

\section{Referensi}

Buku penulis tunggal

Barata. 2003. Manajemen Pelayanan di Indonesia, Gramedia, Jakarta.

Sedarmayanti. 2004. Membangun Sistem Manajemen Kinerja Guna Meningkatkan Produktivitas Menuju Good Governance, Mandar Maju, Bandung.

\section{Buku dengan dua sampai tujuh penulis}

Sinambela, Lijan Poltak. 2008. Reformasi Pelayanan Publik: Teori, Kebijakan, dan Implementasi, PT Bumi Aksara, Jakarta. 
Artikel Jurnal:

Dwiyanto, Agus dkk. 2007. Reformasi Birokrasi di Indonesia, Gajah Mada University Press, Yogyakarta.

Dwiyanto, Agus. 2008. Mewujudkan Good Governance Melalui Pelayanan Publik, Gajah Mada University Press, Yogyakarta.

Nurhasyima. 2000. Jurnal Mengenai Kualitas Pelayanan Publik di Indonesia, Jakarta.

Pramusinto, Agus dan Purwanto, Erwan Agus. 2009. Reformasi Birokrasi,

Kepemimpinan dan Pelayanan Publik : Kajian tentang pelaksanaan otonomi daerah di Indonesia, Gava Media, Yogyakarta.

Saputro, Dicky Agus, dkk, Kedudukan dan perlindungan hukum Tenaga Honorer setelah berlakunya UU No.5 tahun 2014, Jurnal, hal 3.

Sriastuti, Baiq, Kedudukan Tenaga Honorer Berdasarkan Undang - Undang No. 5 Tahun 2014, Jurnal IUS, 2017, Volume V, Nomor 2, hal 285. 